\title{
Neuroendocrine Tumours of Extrahepatic Biliary Tract: Series of Four Cases with Literature Review
}

\author{
Amit Chopde ( $\square$ amitchopde210@yahoo.co.in ) \\ Tata Memorial Centre https://orcid.org/0000-0001-8723-9994 \\ Vikas Gupta \\ Tata Memorial Centre \\ Akshaya Jadhav \\ Tata Memorial Centre \\ Rajiv Kaushal \\ Tata Memorial Centre \\ Mukta Ramadwar \\ Tata Memorial Centre \\ Shraddha Patkar \\ Tata Memorial Centre https://orcid.org/0000-0001-8489-6825

\section{Mahesh Goel} \\ Tata Memorial Centre
}

\section{Research Article}

Keywords: Neuroendocrine tumours (NETs), common bile duct (CBD), FNAC, CECT, RnY HJ

Posted Date: September 29th, 2021

DOI: https://doi.org/10.21203/rs.3.rs-942148/v1

License: (c) (i) This work is licensed under a Creative Commons Attribution 4.0 International License. Read Full License 


\section{Abstract}

Neuroendocrine tumours (NETs) originating from extrahepatic bile duct are an extremely rare entity. They are typically slow growing tumours with malignant potential. Commonly presenting as obstructive jaundice, preoperative clinico-radiologic differentiation between extrahepatic biliary tract neuroendocrine tumours and cholangiocarcinoma is difficult and the final diagnosis is usually established after surgical histopathology and immunohistochemistry examination. R0 resection offers the only curative option with good long term outcomes for Well differentiated NETs (grade1, grade2 and grade3) whilst the aggressive poorly differentiated Neuroendocrine Carcinoma (NEC) needs multimodality approach. We present our experience of management of four cases including three cases of grade II NET and one case of NEC undergoing surgical resection at a single centre with a short review of available literature.

\section{Introduction}

Neuroendocrine tumours (NETs) are rare neoplasms arising from the aggregates of neuroendocrine cells scattered across the human organs. These are indolent tumours with malignant potential, found most commonly in the gastrointestinal tract constituting about $60 \%$ of overall NETs [1]. Primary NETs arising from the biliary tree are extremely rare amounting to only 0.2 to $2 \%$ all gastrointestinal NETs [2]. Within the biliary system they are most commonly found in hepatic ducts and distal common bile duct (CBD) followed by the mid CBD, cystic duct and proximal CBD [3]. Preoperative diagnosis of extrahepatic biliary NETs is challenging owing to clinic-radiological similarity with cholangiocarcinoma. Preoperative cytology has low sensitivity for diagnosis and the submucosal location of these tumours leads to inconclusive cytology reports [4]. There have been less than hundred case reports of extrahepatic bile duct NETs published in the English literature. Here, we present a series of four cases of extrahepatic bile duct neuroendocrine tumours and discuss the challenges faced in the diagnosis and management.

\section{Cases}

\section{Patient 1}

A 58-year-old lady was referred with obstructive jaundice. Contrast enhanced Computerised Tomography scan (CECT) of abdomen showed an enhancing mass at the level of confluence of right and left hepatic ducts. She had direct hyperbilirubinemia and Carbohydrate antigen (CA-19.9) was $86.51 \mathrm{lU} / \mathrm{ml}$. Percutaneous Fine Needle Aspiration Cytology (FNAC) was reported as adenocarcinoma. On re-evaluation, the lesion was seen to extend till Right hepatic duct. Positron emission technology computerised tomography (PET CT) scans ruled out distant metastasis. Left percutaneous transhepatic biliary drainage (PTBD) was performed. Cholangiogram confirmed uninvolved left hepatic duct. The patient underwent right hepatectcomy with extrahepatic bile duct excision (EHBTE) and Roux-en-Y Hepaticojejunostomy (RnY HJ). Surprisingly, the histopathology showed a tumour involving proximal bile duct with cells arranged in nesting pattern with round nucleus, stippled nuclear chromatin and inconspicuous nucleoli. Mitotic count was 2-3/10 hpf and Mib-1 labelling index of 3-4\% with immunohistochemistry being strongly positive for chromogranin and synaptophysin diagnostic of well differentiated NET-grade 2. Resection margins of the duct were free and no lymph nodal involvement was seen. The patient has been under observation since and is disease free at last follow up of 75 months after surgery.

\section{Patient 2 (Fig. 1: a-f)}

32-year-old lady with intermittent jaundice with pruritus in the last 6 months presented with conjugated hyperbilirubinemia with CA 19.9 levels of $147 \mathrm{IU} / \mathrm{ml}$. CECT scan of abdomen showed enhancing soft tissue lesion involving the common hepatic ducts with upstream dilatation. MRCP revealed a Bismuth Type II stricture. Endoscopic retrograde cholangiopancreaticography (ERCP) with plastic stenting was done that showed a stricture at cystic-CBD junction. Brush cytology was suspicious of NET. Gallium 68 DOTANOC PET scan showed enhancing lesion at the confluence of cystic-CBD with no evidence of metastasis. After EHBTE with periportal lymphadenopathy and RnY HJ, it was found to be well differentiated NET; grade II with Mib-1 labelling index of $6-7 \%$. (Fig. 2: a-d) All the tumour margins were free with no nodal metastasis. The patient is disease free at 8 months of follow up. 


\section{Patient 3}

44-year-old lady presented with symptoms of pain in abdomen and jaundice. CECT scan showed a heterogeneous enhancing hilar mass. Magnetic resonance cholangiopancreatography (MRCP) showed a hilar mass with Bismuth Type II lesion. Bilateral PTBD with cholangiogram confirmed the same. Bile cytology showed adenocarcinoma cells. She underwent EHBTE with RnY HJ. To our surprise, final histopathology showed large cell neuroendocrine carcinoma (NEC) at the confluence of hepatic ducts involving the muscular layer of common hepatic duct. Marked nuclear atypia with prominent nucleoli, and large areas of necrosis was seen with mitotic count of 5/hpf (brisk mitosis). Mib1 labelling index was 60-70\%. (Fig. 2: e-h) Resection margins were free and lymph nodes were reactive. She was detected to have recurrence in a peripancreatic node $(2 \mathrm{~cm})$ which was FDG avid on PETCT on follow up after 3 months. She was treated with Cisplatin and Etoposide based chemotherapy but had disease progression and finally succumbed after 15 months.

Patient 4 (Fig. 3: a-d)

A 49-year-old gentleman was referred one month after open cholecystectomy for symptomatic gallstone disease. Intraoperatively, there was a mass lesion adjacent to the neck of gallbladder. Histopathology showed chronic cholecystitis. He developed jaundice for a brief period following surgery which resolved on its own. On cross sectional imaging, an irregular heterogeneously enhancing lesion was seen in gallbladder fossa compressing the proximal CBD with upstream dilatation. Suspecting residual carcinoma of gallbladder, he was further staged with an 18-FDG PET CT, which ruled out metastasis. Percutaneous biopsy of lesion was found to be grade I NET (Mib1 labelling index 1\%). Liver function tests, tumour markers were normal. DOTANOC PET scan showed a localised disease and the patient underwent EHBTE and RnY HJ. The tumour was found to be arising from the wall of the CBD without luminal compromise (intramural extraluminal). He had an uneventful postoperative recovery. Histopathology revealed Grade II (Mib index - 5\%) well differentiated NET with tumour free margins and reactive nodes. At 8 months of follow up period, the patient is healthy and recurrence free. Case details are summarised in Table 1.

\section{Discussion}

Neuroendocrine tumours are rare tumours with variable malignant potential. First described as carcinoids by Lubarsch in 1888 , latest WHO classification of 2019 divides them into well differentiated NETs of various grades (1to 3) and aggressive NEC based upon the differentiation and biologic aggression [5,6]. Primary extrahepatic biliary tract (EHBT) NETs are uncommon, probably due to scarce presence of enterochromaffin cells in the bile duct [2]. Though Pilz reported the first case of carcinoid tumour of the common bile duct in 1961, there is limited literature on primary NETs of biliary origin. [7] Here we share our experience with four cases of resectable primary extrahepatic biliary NETs out of which three turned out to be grade II NET and one had NEC.

The etiology of biliary NETs is poorly understood. With no proven predisposing factors, it is hypothesised that chronic inflammation of biliary system arising from stones or congenital malformation induces intestinal metaplasia leading to malignancy [8, 9]. Michalopoulos et al found that $19.2 \%$ cases had associated cholelithiasis. Association with Von HippelLindau syndrome, Multiple Endocrine Neoplasia (MEN-I) syndrome, or the Zollinger-Ellison syndrome has also been reported [10].

The extrahepatic biliary NETs are more common in females with a male to female ratio of 1: 1.5. In our series also 3 out of 4 patients were females. The median age in our series was 46 years which is same as that reported in literature and lesser than that for cholangiocarcinoma $[10,11]$. Clinically, they most commonly present with biliary obstruction (100\% in our series) but in recent times they are increasingly being diagnosed as incidental finding on cross sectional imaging [12]. Although NETs have the potential to secret neuropeptide hormones, the EHBT NETs are usually non-functioning and carcinoid syndrome is very rare even in metastatic disease [11].

Despite technical advances, establishing the diagnosis of extrahepatic biliary NETs preoperatively is painstakingly difficult. In most cases it comes across as a histopathological surprise. The radiological differentiation between the closest differential i.e.

Page $3 / 10$ 
cholangiocarcinoma and biliary NETs is challenging due to similarities in the imaging findings. However, biliary NETs have been found to be hyper dense in arterial phase and more localized to the primary location without invading the surrounding structures than their cholangiocarcinoma counterparts [13]. Brush cytology specimen obtained via ERCP, Percutaneous transhepatic cholangiography or endoscopic ultrasound guided FNAC can provide the histological diagnosis but this potential is marred by the high false negative rates owing to the submucosal location of these tumours [4, 14]. Achieving preoperative tissue diagnosis is desirable in NETs as it helps in selecting the modality for further staging in the form of DOTA PET and/or FDG PET scans. We could achieve preoperative histological diagnosis in two of the four patients which lead to further staging by DOTA PET scans. Though the prognostic value of Chromogranin A has not been established, it has been used to monitor the treatment response assessment and to detect recurrence in follow up. [15]

Surgical resection remains the only curative option for these tumours with the extent of resection determined by the location of the tumour. While mid CBD NETs can be treated with extrahepatic biliary tract excision, distal involvement may require pancreaticoduodenectomy to achieve adequate margins. Similarly, proximal hepatic duct involvement may warrant a hepatectomy to achieve R0 resection. Regional periportal lymphadenectomy has been advocated by National Comprehensive Cancer Network guidelines and some authors [16]. In current series, three patients underwent EHBTE while one required additional right hepatectomy to achieve free margins. R0 resection was obtained in all the patients. Regional periportal nodal dissection was also done in all the cases. Role of neoadjuvant therapy for Biliary NETs is still not clearly defined but adjuvant chemotherapy with Cisplatin and Etoposide has been shown to have good results in cases of high grade NET (grade 3 ) and NEC $[16,17]$. For locally advanced unresectable or metastatic extrahepatic biliary NETs, many treatment options like systemic chemotherapy, somatostatin analogues, liver directed therapies such as chemoembolisation or radioembolisation, peptide receptor nucleotide therapy to Liver transplantation have been described.[18]

The prognosis of biliary NETs varies as per their biologic aggressiveness. Distinction between NETs and NECs is made on the basis of nuclear atypia, mitoses and necrosis. The well differentiated NETs have organoid architecture and uniform nuclear features and may have minimal necrosis, while NECs are often seen in sheets and less nested pattern and further classified into Small cell NEC and Large cell NEC. While low grade I, II NETs tend to be indolent and slow growing with good prognosis, higher grade III NETs and NECs are aggressive with poor prognosis. Low grade NETs have shown to have excellent survival after radical resection with a 10-year survival of $80 \%$ whereas the poorly differentiated NEC has a dismal prognosis with majority of the patients succumbing to the disease within 1 year of surgery and a median survival of 9.6 months $[19,20]$. In our series, the patient with NEC had progression on chemotherapy with overall survival of 15 months. In comparison, other patients with grade II NETs are recurrence free with one person at 75 months and two others at 8 months follow up each.

In conclusion, preoperative differentiation between cholangiocarcinoma and biliary NETs remains difficult despite all technological advances. However, preoperative diagnosis is desirable as it can lead to further staging in the form of functional DOTA-PET or FDG PET scans enabling comprehensive decision making. Radical resection with regional lymphadenectomy is curative treatment for biliary NETs especially for well differentiated tumours and has good prognosis. Poorly differentiated NEC is rare, aggressive variant with dismal prognosis which needs to be managed with multidisciplinary approach.

\section{Abbreviations}

NET: Neuroendocrine tumour

NEC: Neuroendocrine carcinoma

CBD: common bile duct

CECT: Contrast enhanced Computerised Tomography

CA-19.9: Carbohydrate antigen

CEA: Carcinoembryonic antigen 
FNAC: Fine Needle Aspiration Cytology

PET CT: Positron emission technology computerised tomography

FDG: Flurodeoxy Glucose

PTBD: Percutaneous transhepatic biliary drainage

EHBTE: Extrahepatic biliary tract excision

RnY HJ: Roux en Y Hepaticojejunostomy

HPF: High power Field

IHBRD: intra hepatic biliary radical dilatation

MRCP: Magnetic resonance cholangiopancreatography

ERCP: Endoscopic retrograde cholangiopancreaticography

DOTA: 1, 4, 7, 10-tetraazacyclododecane tetraacetic acid 1-Nal ${ }^{3}$-octreotide

NOC: 1-Nal ${ }^{3}$-octreotide

WHO: World Health organisation

EHBT: extrahepatic biliary tract

\section{Declarations}

\section{Funding: None}

Conflicts of interest/Competing interests: None

Availability of data and material: Not applicable

Code availability: Not applicable

Ethics Approval : Taken

Consent to Participate Yes

Consent for Publication Yes

Author Contributions

Conceptualization:

Shraddha Patkar, Mahesh Goel, Mukta Ramadwar

Data curation:

Amit Chopde, Akshaya Jadhav,Rajiv Kaushal

Project administration:

Shraddha Patkar, Mukta Ramadwar 
Visualization:

Shraddha Patkar, Amit Chopde, Akshaya Jadhav

Writing - original draft:

Amit Chopde, Vikas Gupta,Rajiv Kaushal

Writing - review \& editing:

Shraddha Patkar, Mukta Ramadwar, Mahesh Goel

\section{References}

1. Maggard MA, O'Connell JB, Ko CY. Updated population-based review of carcinoid tumors. Annals of surgery. 2004 Jul;240(1):117.

2. Chamberlain RS, Blumgart LH. Carcinoid tumors of the extrahepatic bile duct: a rare cause of malignant biliary obstruction. Cancer. 1999 Nov 15; 86(10):1959-65.

3. Hosoda K, Kobayashi A, Shimizu A, Kitagawa N, Ito T, Yamada A, et al. Neuroendocrine tumor of the common bile duct. Surgery. 2016;160(2):525-6.

4. Govil H, Reddy V, Kluskens L, Treaba D, Massarani-Wafai R, Selvaggi S, et al. Brush cytology of the biliary tract: retrospective study of 278 cases with histopathologic correlation. Diagnostic cytopathology. 2002 May; 26(5):273-7.

5. Thompson GB, Van Heerden JA, Martin JK Jr, Schutt AJ, Ilstrup DM, Carney JA. Carcinoid tumors of the gastrointestinal tract: presentation, management, and prognosis. Surgery. 1985 Dec 1;98(6):1054-63.

6. Nagtegaal ID, Odze RD, Klimstra D, Paradis V, Rugge M, Schirmacher P, et al. WHO Classification of Tumours Editorial Board. The 2019 WHO classification of tumours of the digestive system. Histopathology. 2020 Jan; 76(2):182-188.

7. Pilz E. On carcinoid of the bile duct. Zentralblatt Fur Chirurgie. 1961 Jul 8; 86:1588-90.

8. Sasatomi E, Nalesnik MA, Marsh JW. Neuroendocrine carcinoma of the extrahepatic bile duct: case report and literature review. World Journal of Gastroenterology: WJG. 2013 Jul 28;19(28):4616-23.

9. Park SB, Moon SB, Ryu YJ, Hong J, Kim YH, Chae GB, et al. Primary large cell neuroendocrine carcinoma in the common bile duct: first Asian case report. World J Gastroenterol. 2014 Dec;21(47):18048-52. 20(.

10. Michalopoulos N, Papavramidis TS, Karayannopoulou G, Pliakos I, Papavramidis ST, Kanellos I. Neuroendocrine tumors of extrahepatic biliary tract. Pathol Oncol Res. 2014 Oct; 20(4):765-75.

11. Yasuda T, Imai G, Takemoto M, Yamasaki M, Ishikawa H, Kitano M, et al. Carcinoid tumor of the extrahepatic bile duct: report of a case. Clinical journal of gastroenterology. 2013 Apr 1; 6(2):177-87.

12. Lawrence B, Gustafsson BI, Chan A, Svejda B, Kidd M, Modlin IM. The epidemiology of gastroenteropancreatic neuroendocrine tumors. Endocrinol Metab Clin North Am. 2011;40(1).

13. Hong N, Kim HJ, Byun JH, Kim SY, Kim KW, Kim JH, et al. Neuroendocrine neoplasms of the extrahepatic bile duct: radiologic and clinical characteristics. Abdominal imaging. 2015 Jan;40(1):181-91.

14. Noronha YS, Raza AS. Well-differentiated neuroendocrine (carcinoid) tumours of the extrahepatic biliary ducts. Arch Pathol Lab Med. 2010 Jul;134(7):1075-9.

15. Prestifilippo A, Blanco G, Vitale MP, Giuffrida D. Chromogranin A and neuroendocrine tumors. Neuroendocrine Tumor Croatia: InTech. 2012 Jun;5:11-7.

16. Liu Z, Zhang DY, Lu Z, Zhang P, Sun WL, Ma X, et al. Neuroendocrine tumor of the common bile duct: a case report and review of the literature. OncoTargets therapy. 2018;11:2295.

17. Iwasa S, Morizane C, Okusaka T, Ueno H, Ikeda M, Kondo S, et al. Cisplatin and etoposide as first-line chemotherapy for poorly differentiated neuroendocrine carcinoma of the hepatobiliary tract and pancreas. Jpn J Clin Oncol. 2010 Apr;40(4):313-8. 
18. Walter T, Brixi-Benmansour H, Lombard-Bohas C, Cadiot G. New treatment strategies in advanced neuroendocrine tumours. Dig Liver Dis. 2012 Feb;44(2):95-105.

19. Albores-Saavedra J, Batich K, Hossain S, Henson DE, Schwartz AM. Carcinoid tumors and small-cell carcinomas of the gallbladder and extrahepatic bile ducts: a comparative study based on 221 cases from the Surveillance, Epidemiology, and End Results Program. Ann Diagn Pathol. 2009 Dec;13(6):378-83.

20. Kim J. Lee WJ, Lee SH. Lee KB, Ryu JK. Kim YT et al. Clinical features of 20 patients with curatively resected biliary neuroendocrine tumours. Dig Liver Dis. 2011 Dec; 43(12):965-70.

\section{Tables}

Table No 1: Summary of cases

\begin{tabular}{|c|c|c|c|c|c|c|c|c|}
\hline $\begin{array}{l}\text { SR } \\
\text { No }\end{array}$ & $\begin{array}{l}\text { Age/ } \\
\text { Sex }\end{array}$ & Location & $\begin{array}{l}\text { Bismuth } \\
\text { Type }\end{array}$ & $\begin{array}{l}\text { Biliary } \\
\text { drainage }\end{array}$ & $\begin{array}{l}\text { Preop Diagnosis/ } \\
\text { Modality used }\end{array}$ & Surgery & Histopathology & $\begin{array}{l}\text { Last } \\
\text { follow up } \\
\text { Status/ } \\
\text { Survival }\end{array}$ \\
\hline 1) & $58 / F$ & $\begin{array}{l}\text { Common } \\
\text { hepatic } \\
\text { duct/Right } \\
\text { hepatic } \\
\text { duct }\end{array}$ & $\begin{array}{l}\text { Type } \\
\text { IIIA }\end{array}$ & $\begin{array}{l}\text { Left } \\
\text { PTBD }\end{array}$ & $\begin{array}{l}\text { Adenocarcinoma } \\
\text { (PercutaneousFNAC) }\end{array}$ & $\begin{array}{l}\text { Right } \\
\text { hepatectcomy, } \\
\text { EHBTE +RnY } \\
\text { HJ }\end{array}$ & $\begin{array}{l}\text { Grade II } \\
\text { NET }\end{array}$ & $\begin{array}{l}\text { Disease } \\
\text { free } \\
75 \\
\text { months }\end{array}$ \\
\hline 2) & $32 / F$ & $\begin{array}{l}\text { Cystic } \\
\text { CBD } \\
\text { junction }\end{array}$ & Type II & ERCP & $\begin{array}{l}\text { NET } \\
\text { (Brushing cytology) }\end{array}$ & $\begin{array}{l}\text { EHBTE +RnY } \\
\text { HJ }\end{array}$ & $\begin{array}{l}\text { Grade II } \\
\text { NET }\end{array}$ & $\begin{array}{l}\text { Disease } \\
\text { free } \\
8 \text { months }\end{array}$ \\
\hline 3) & $44 / F$ & $\begin{array}{l}\text { Common } \\
\text { hepatic } \\
\text { duct }\end{array}$ & Type II & $\begin{array}{l}\text { B/L } \\
\text { PTBD }\end{array}$ & $\begin{array}{l}\text { Adenocarcinoma } \\
\text { (Brushing cytology) }\end{array}$ & $\begin{array}{l}\text { EHBTE +RnY } \\
\text { HJ }\end{array}$ & $\begin{array}{l}\text { Poorly } \\
\text { differentiated } \\
\text { NEC }\end{array}$ & $\begin{array}{l}\text { Deceasec } \\
\text { OS : } 15 \\
\text { month } \\
\text { DFS : } 3 \\
\text { months }\end{array}$ \\
\hline 4) & $49 / \mathrm{M}$ & $\begin{array}{l}\text { Common } \\
\text { bile duct }\end{array}$ & Type I & $\begin{array}{l}\text { Not } \\
\text { done }\end{array}$ & $\begin{array}{l}\text { NET } \\
\text { (Percutaneous } \\
\text { biopsy) }\end{array}$ & $\begin{array}{l}\text { EHBTE +RnY } \\
\text { HJ }\end{array}$ & $\begin{array}{l}\text { Grade II } \\
\text { NET }\end{array}$ & $\begin{array}{l}\text { Disease } \\
\text { free } \\
8 \text { months }\end{array}$ \\
\hline
\end{tabular}

Figures 


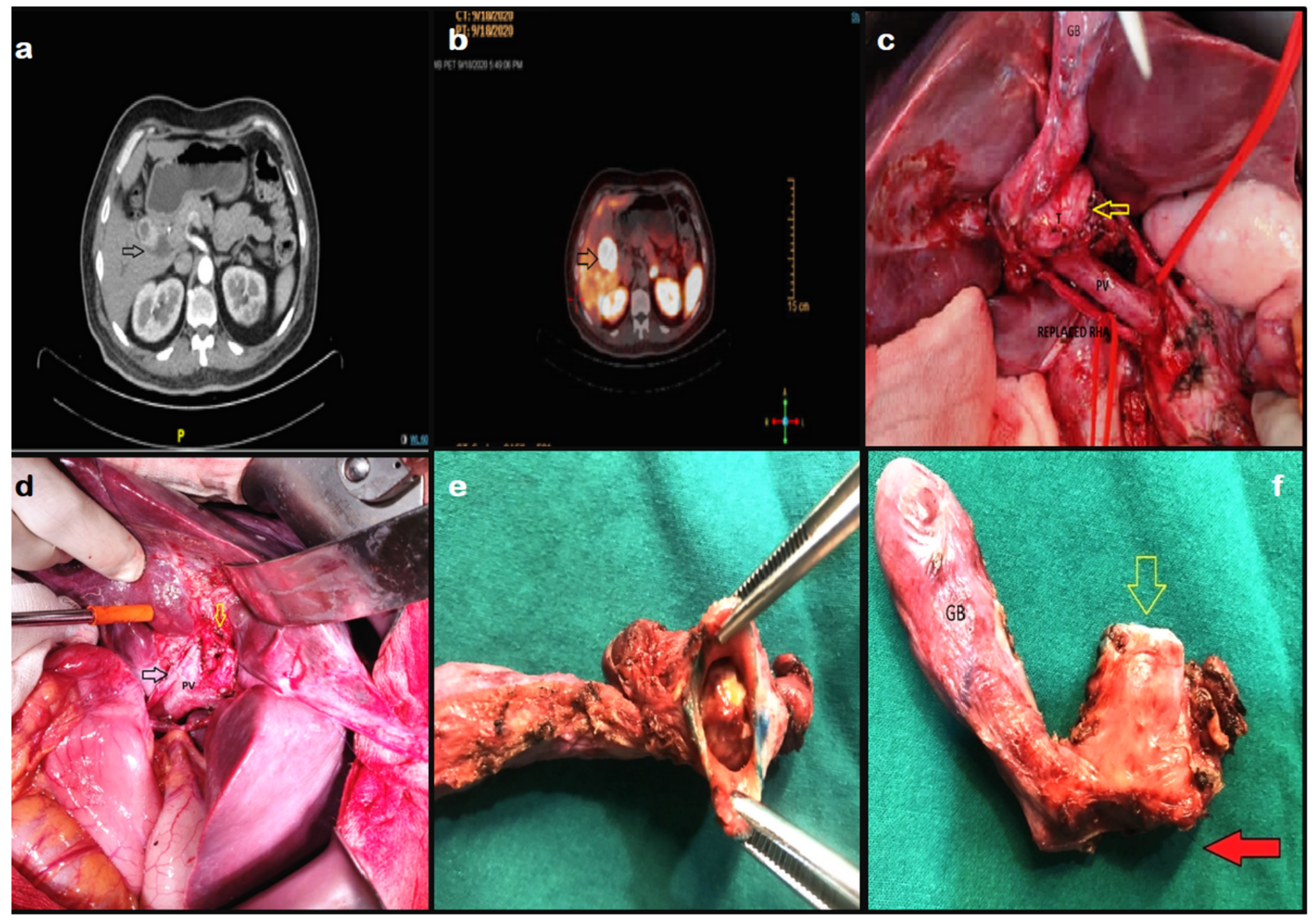

Figure 1

a -CECT; b- DOTANOC scan; (Arrow points to tumour) c- Intraoperative Findings (Distal end of CBD has been cut with proximal end intact) (T: Tumour GB: Gallbladder PV: portal vein Arrow pointer: cut end of distal CBD) d- Post resection tumour bed (PV: Portal vein; Black Arrow: Replaced RHA; Yellow arrow: Proximal margin at CHD) e- Cut Open specimen showing intraluminal tumour f-Surgical Specimen (GB: Gall bladder; Yellow Arrow: proximal end CHD Red Arrow: Distal CBD cut end) 

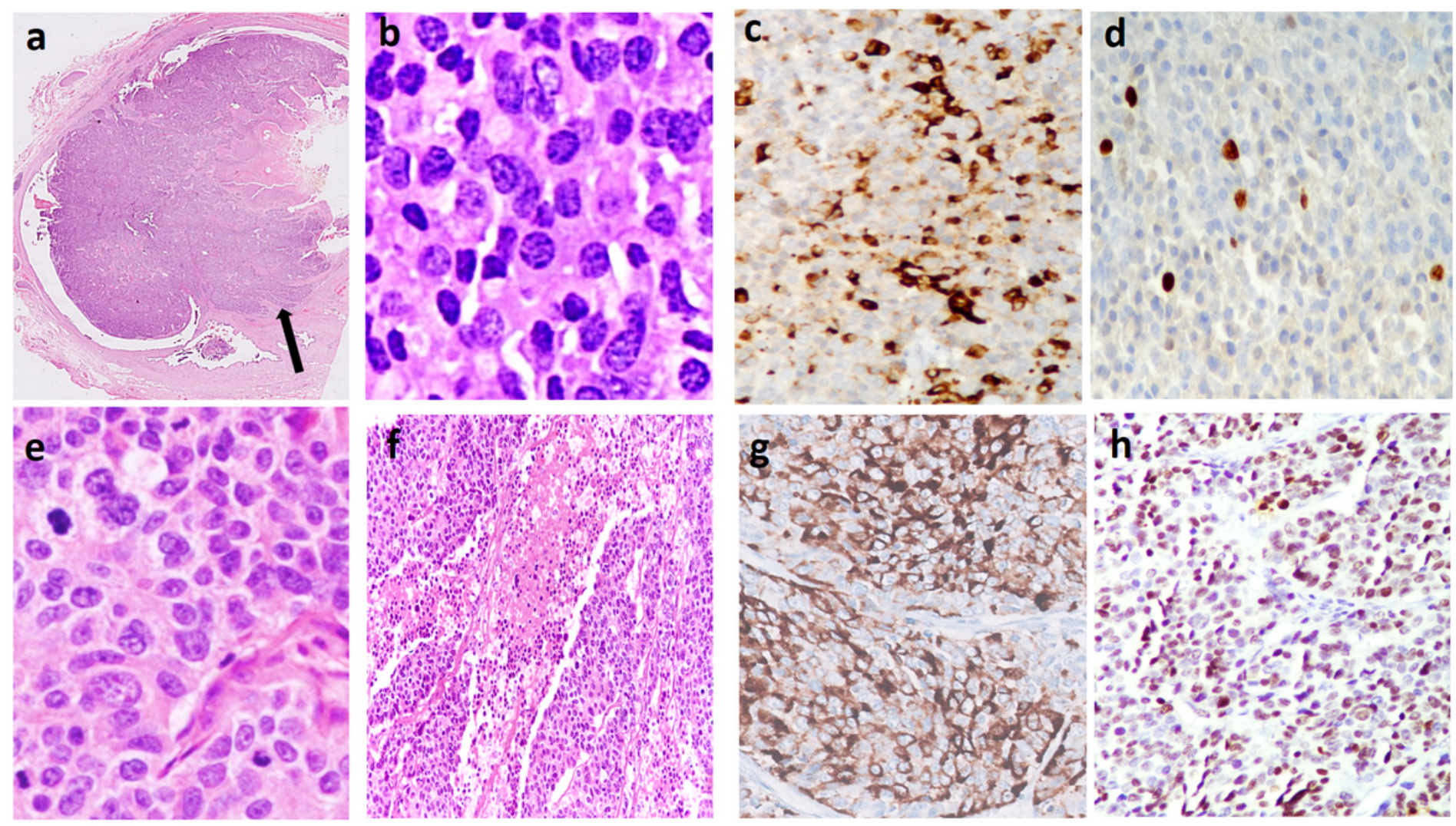

\section{Figure 2}

a-d) Microscopic features of Neuroendocrine tumour, grade 2, a) Common bile duct wall with Neuroendocrine tumour in the lumen with infiltration into the wall (black arrow). $\mathrm{H}$ and $\mathrm{E} \times 20 \mathrm{~b}$ ) Uniform tumour cells with occasional mitosis (2-3/10 hpf) and no necrosis. $\mathrm{H}$ and $\mathrm{E} \times 400 \mathrm{c}$ ) Strong cytoplasmic staining for chromogranin on immunohistochemistry, DAB $\times 400 \mathrm{~d}$ ) IHC for Mib-1labelling index 6-7\%. DAB x 400 

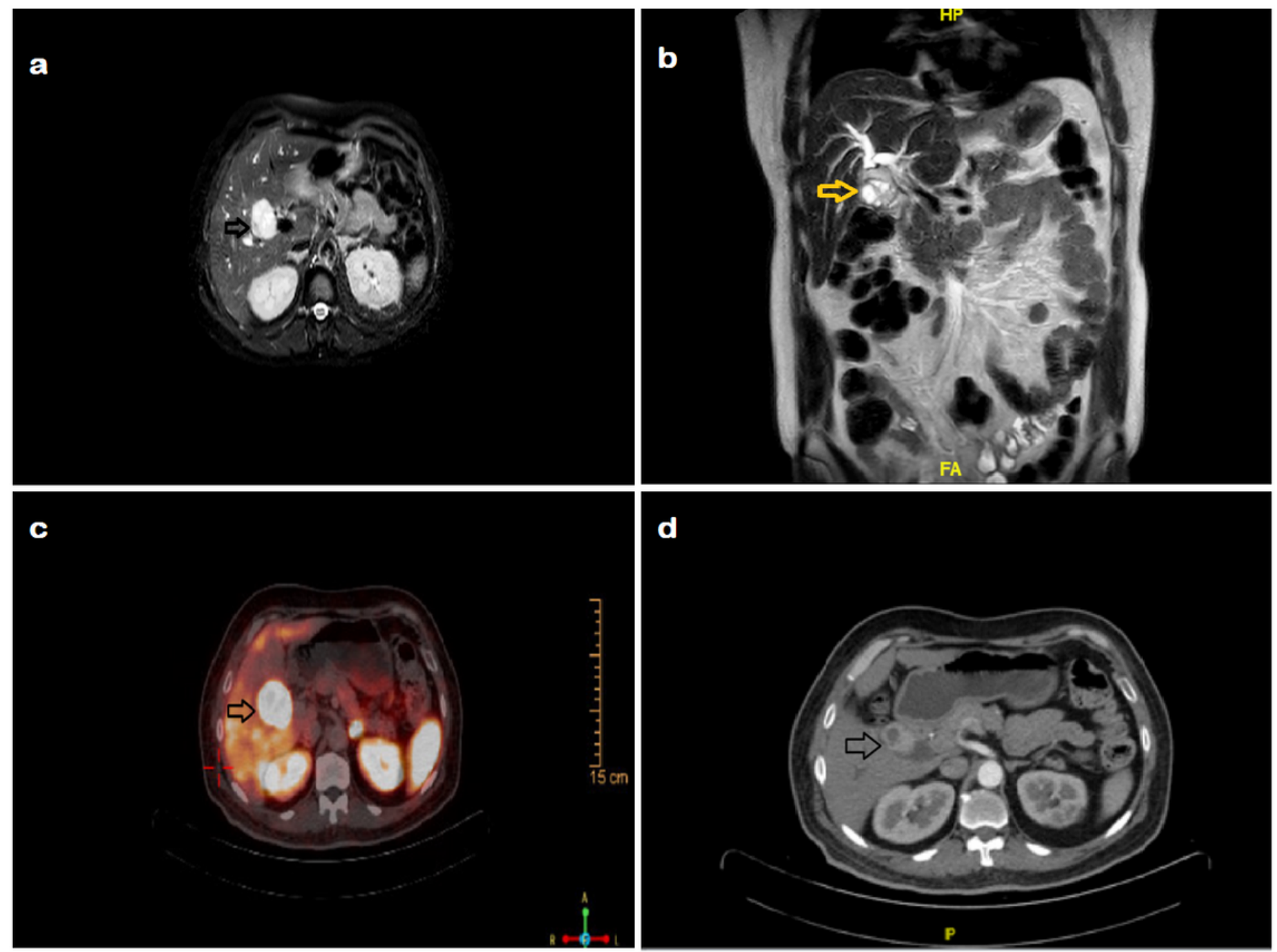

\section{Figure 3}

a- MRl; b- MRCP; c- DOTANOC; d- CECT (Arrow showing tumour location) (e-h) Microscopic features of large cell Neuroendocrine carcinoma, e) The tumour cells with solid growth pattern, marked nuclear atypia, prominent nucleoli, brisk mitotic activity (5/hpf), H and E x 400 f) NEC with conspicuous areas of necrosis. H and E x $100 \mathrm{~g}$ ) Strong cytoplasmic staining for chromogranin on immunohistochemistry, DAB x400 h) The Mib-1 index in the highest proliferating areas is $60-70 \%, D A B \times 400$ 